\title{
Genomic Signature of the Natural Oncolytic Herpes Simplex Virus HF10 and Its Therapeutic Role in Preclinical and Clinical Trials
}

\begin{abstract}
Ibrahim Ragab Eissa 1,2,3, Yoshinori Naoe ${ }^{1}$, Itzel Bustos-Villalobos', Toru Ichinose', Maki Tanaka ${ }^{4}$, Wu Zhiwen ${ }^{1,2}$, Nobuaki Mukoyama ${ }^{5}$, Taishi Morimoto ${ }^{2}$, Noriyuki Miyajima ${ }^{6}$, Hasegawa Hitoki ${ }^{7}$, Seiji Sumigama ${ }^{7}$, Branko Aleksic ${ }^{7}$, Yasuhiro Kodera ${ }^{2}$ and Hideki Kasuya ${ }^{1 *}$

${ }^{1}$ Cancer Immune Therapy Research Center, Graduate School of Medicine, Nagoya University, Nagoya, Japan, ${ }^{2}$ Department of Surgery II, Graduate School of Medicine, Nagoya University, Nagoya, Japan, ${ }^{3}$ Faculty of Science, Tanta University, Tanta, Egypt, ${ }^{4}$ Takara Bio Inc., Otsu, Japan, ${ }^{5}$ Department of Otolaryngology, Graduate School of Medicine, Nagoya University, Nagoya, Japan, ${ }^{6}$ Department of Transplantation and Endocrine Surgery, Graduate School of Medicine, Nagoya University, Nagoya, Japan, ${ }^{7}$ Office of International Affairs, Graduate School of Medicine, Nagoya University, Nagoya, Japan
\end{abstract}

OPEN ACCESS

Edited by:

Joshua Pesach Rosenzweig,

Cell-El Ltd., Israel

Reviewed by:

Zong Sheng Guo,

Harvard University, United States Amod Ashok Sarnaik, Moffitt Cancer Center, United States

${ }^{*}$ Correspondence: Hideki Kasuya kasuya@med.nagoya-u.ac.jp

Specialty section: This article was submitted to Cancer Immunity and Immunotherapy, a section of the journal Frontiers in Oncology

Received: 28 April 2017 Accepted: 26 June 2017 Published: 14 July 2017

Citation:

Eissa IR, Naoe Y, Bustos-Villalobos I, Ichinose T, Tanaka M, Zhiwen W, Mukoyama N, Morimoto T, Miyajima N, Hitoki H, Sumigama S, Aleksic B, Kodera $Y$ and Kasuya $H$ (2017) Genomic Signature of the Natural Oncolytic Herpes Simplex Virus HF10 and Its Therapeutic Role in Preclinical and Clinical Trials.

Front. Oncol. 7:149. doi: 10.3389/fonc.2017.00149
Oncolytic viruses (OVs) are opening new possibilities in cancer therapy with their unique mechanism of selective replication within tumor cells and triggering of antitumor immune responses. HF10 is an oncolytic herpes simplex virus- 1 with a unique genomic structure that has non-engineered deletions and insertions accompanied by frame-shift mutations, in contrast to the majority of engineered OVs. At the genetic level, HF10 naturally lacks the expression of UL43, UL49.5, UL55, UL56, and latency-associated transcripts, and overexpresses UL53 and UL54. In preclinical studies, HF10 replicated efficiently within tumor cells with extensive cytolytic effects and induced increased numbers of activated $\mathrm{CD}^{+}$and $\mathrm{CD}^{+} \mathrm{T}$ cells and natural killer cells within the tumor, leading to a significant reduction in tumor growth and prolonged survival rates. Investigator-initiated clinical studies of HF10 have been completed in recurrent breast carcinoma, head and neck cancer, and unresectable pancreatic cancer in Japan. Phase I trials were subsequently completed in refractory superficial cancers and melanoma in the United States. HF10 has been demonstrated to have a high safety margin with low frequency of adverse effects in all treated patients. Interestingly, HF10 antigens were detected in pancreatic carcinoma over 300 days after treatment with infiltration of $\mathrm{CD}^{+}$and $\mathrm{CD}^{+} \mathrm{T}$ cells, which enhanced the immune response. To date, preliminary results from a Phase II trial have indicated that HF10 in combination with ipilimumab (anti-CTLA-4) is safe and well tolerated, with high antitumor efficacy. Improvement of the effect of ipilimumab was observed in patients with stage IIIb, IIIc, or IV unresectable or metastatic melanoma. This review provides a concise description of the genomic functional organization of HF10 compared with talimogene laherparepvec. Furthermore, this review focuses on HF10 in cancer treatment as monotherapy as well as in combination therapy through a concise description of all preclinical and clinical data. In addition, we will address approaches for future directions in HF10 studies as cancer therapy.

Keywords: herpes simplex oncolytic viruses, genomic structure, HF10, talimogene laherparepvec, preclinical studies, combination therapy, clinical trials, future directions 


\section{INTRODUCTION}

Oncolytic viruses (OVs) are currently being used effectively with therapeutic drugs to change the landscape of cancer treatment. OVs are considered immunotherapeutic targeted agents due to their selective replication within tumor cells and enhancement of the immune response. As a consequence, recent advances in viral genomics and tumor immunology have addressed OVs as a type of cancer therapy. To date, over 30 OVs belonging to seven DNA or RNA virus families have been successfully translated from preclinical studies to clinical trials (Table 1) (1). The Herpesviridae family includes human alphaherpesvirus-1 [Herpes simplex virus-1 (HSV-1)]. HSV-1 is the first human herpesvirus to be discovered and the most intensively investigated virus (2). The HSV family has common features, such as double stranded DNA (dsDNA) and an icosahedral capsid (3). The HSV family has taken precedence over other families in cancer treatment. For example, dlsptk, a type of HSV-1 virus, was the first OV to be engineered by deletion of HSV thymidine kinase (4). Talimogene laherparepvec (T-Vec, Imlygic ${ }^{\mathrm{TM}}$ formerly Oncovex ${ }^{\mathrm{GM}-\mathrm{CSF}}$ ), an HSV-1 virus encoding granulocyte macrophage colony-stimulating factor (GM-CSF), was the first OV approved by the US Food and Drug Administration for the treatment of melanoma (5).

Most OVs, including the approved T-Vec, have been engineered to increase tumor selectivity and efficacy. HF10, on the other hand, is a spontaneously mutated virus without any insertion of foreign genes. The HF10 genome consists of linear dsDNA with a natural deletion of $6,127 \mathrm{~kb}$ and insertions of 6,027 bp accompanied by frame-shift mutations located at different nucleotide positions within the genome. These deletions and insertions caused a loss of expression of UL43, UL49.5, UL55, UL56, and latency-associated transcript (LAT) genes and overexpression of UL53 and UL54. Many investigators have evaluated the effect of these deletions on the oncolytic characteristics of HF10 in different cell lines as well as tumor models of colon cancer, breast cancer, bladder cancer, pancreatic cancer, and melanoma. Preclinical studies have found that HF10: (a) has high innate tumor selectivity, (b) has high viral replication, (c) induces a complete cytopathic effect, (d) mediates a highly potent bystander effect, and (e) has potent antitumor efficacy against different malignancies. Consequently, preclinical studies have translated into successful clinical trials with promising results in different cancer types including recurrent metastatic breast cancer, recurrent head and neck squamous cell carcinoma (HNSCC), advanced pancreatic cancer, refractory and superficial cancers, and melanoma. Recently, there has been a lot of effort to establish the full layout of HF10 as an OV in cancer treatment. This review outlines a detailed approach for using HSV-HF10 as an OV. We will address the similarities and differences of the genomic structures of HF10, T-Vec, and other HSV OVs. Furthermore, we will describe the effect of the natural deletions in HF10 on its oncolytic efficacy in cancer treatment through a concise review of all preclinical studies and clinical trials, comparing it to genetically engineered viruses such as T-Vec. Finally, we will outline future directions for preclinical and clinical studies.

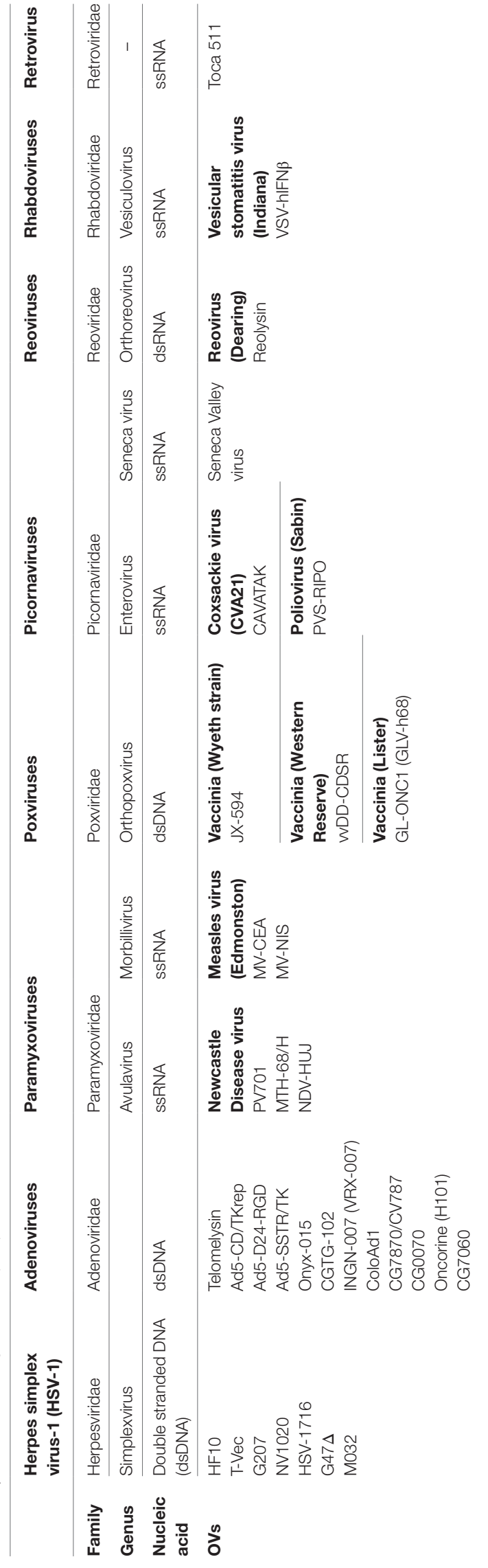




\section{HF10 Virion Structure}

HF10 was originally purified from the HSV-1 strain HF as HF clone 10 (HF10) (6). The HF10 virion is similar to other HSV-1 virions. Early studies revealed that the HSV virion consists of four elements as shown in Figure 1: (a) a core containing linear dsDNA wrapped as a toroid or spool with the negative charges of DNA neutralized by polyamines (spermine and spermidine); (b) an icosahedral capsid comprised of 162 capsomers arranged in a $T=16$ symmetry containing a nucleocapsid in the outer layer composed of four viral proteins (VP) plus VP5 as the major capsid protein; (c) a tegument consisting of an unstructured proteinaceous layer surrounding the capsid composed of $18 \mathrm{VP}$ with VP16 as the most notable; and (d) an envelope, consisting of glycoproteins $\mathrm{gB}, \mathrm{gC}, \mathrm{gD}, \mathrm{gE}, \mathrm{gG}, \mathrm{gH}, \mathrm{gI}, \mathrm{gK}$, $\mathrm{gL}$, and $\mathrm{gM}(7,8)$. HF10 lacks UL49.5 that encodes gN, which links with gM (UL10 protein) to form a disulfide-linked complex (9). Moreover, HF10 overexpresses UL53, which encodes gK, a regulator of the egression process of the HSV virion from infected cells (10).

\section{GENOMIC STRUCTURES OF HF10 AND T-Vec}

To date, there are 17 strains of HSV-1 that have been isolated (ICTV 2015 taxonomy). Seven genomes have been completely or partially sequenced. HSV HF17 (NC_001806, X14112) is often used as a reference for genome sequence comparison (11). The HF10 genome was the first HSV genome to be completely sequenced, while $\mathrm{T}-\mathrm{Vec}$ has only been partially sequenced. The HF10 and T-Vec genomes have the following similarities (Figure 2). (a) Both genomes are made up of linear dsDNA. (b) Each genome is composed of two unique inverted sequences, a unique long sequence (UL) flanked by a terminally repeated long sequence $\left[T R L=\left(a_{L}, b\right)\right]$, and an internally repeated long sequence $\left[\operatorname{IRL}=\left(\mathrm{b}^{\prime} \mathrm{a}^{\prime}\right)\right]$. (c) Each genome also has a unique short sequence designated as (US) bracketed by a terminally repeated short sequence $[$ TRS $=(c, a)]$, and an internally repeated short sequence $\left[\operatorname{IRS}=\left(c^{\prime} a^{\prime}\right)\right](12,13)$.

HF10 differs from T-Vec in their strain origins and their genomic deletions and insertions panel (Table 2). T-Vec was genetically modified from the JS1 strain to improve tumor-selective replication and immune response. As shown in Figure 2B, both copies of the ICP34.5 gene have been deleted from the parent virus genome to suppress its replication in normal tissues. The ICP47 gene has also been deleted to increase the expression of MHC class I on infected cells. Moreover, the hGM-CSF cassette has been inserted in lieu of the ICP34.5 gene loci to enhance the antitumor cytotoxic immune response. Expression of hGM-CSF is derived from the cytomegalovirus and polyadenylation signal (pA) (bovine growth hormone) immediate early promoters, respectively (13).

HF10 has natural deletions and insertions within the genome. The UL56/IRL junction has been deleted from 116.515 bp to $120.346 \mathrm{bp}$, leading to the lack of expression of UL56 and LATs (Figure 2A). In addition, 2,295 bp of the TRL has also been deleted and replaced by 6,027 bp that express the UL52 partial, UL53, UL54, UL55, and UL56 inverted sequences. Both deletions and insertions lead to duplicated copies of UL53, UL54, UL55, two incomplete copies of $U L 56$, and one complete and one incomplete copy of UL52. Frame-shift mutations in the N-terminal region cause a loss of the functional expression of the UL43 and UL49.5 gene products (12).

As noted above, the deletions cause the gene products of $U L 43$, UL49.5, UL55, UL56, and LAT to not be expressed, whereas duplication leads to UL53 and UL54 overexpression. The main question here is "What are the functions of the deleted and duplicated genes and their effect on HF10 antitumor efficacy?" To answer this question, the function of the deleted genes must be known.

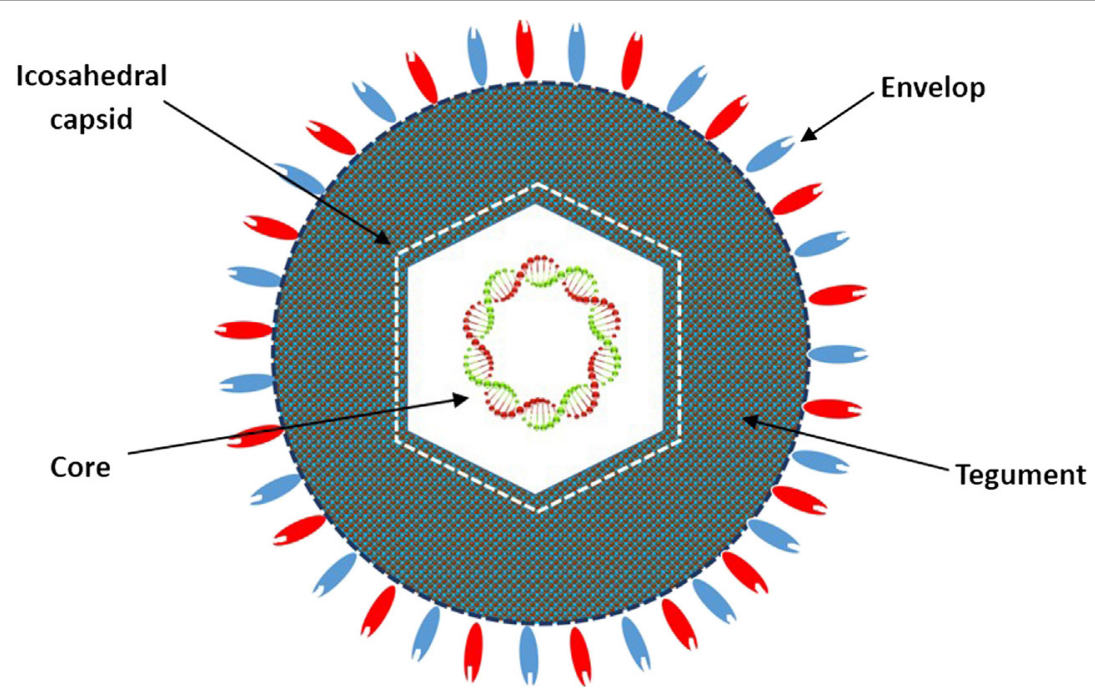

FIGURE 1 | Diagrammatic structure of the HF10 virion. The HF10 virion is composed of four elements: envelope, contains glycoprotein receptors; Tegument, consists of viral proteins; Icosahedral capsid, comprised of capsomers and a nucleocapsid in the outer layer; and Core, contains linear double stranded DNA. 


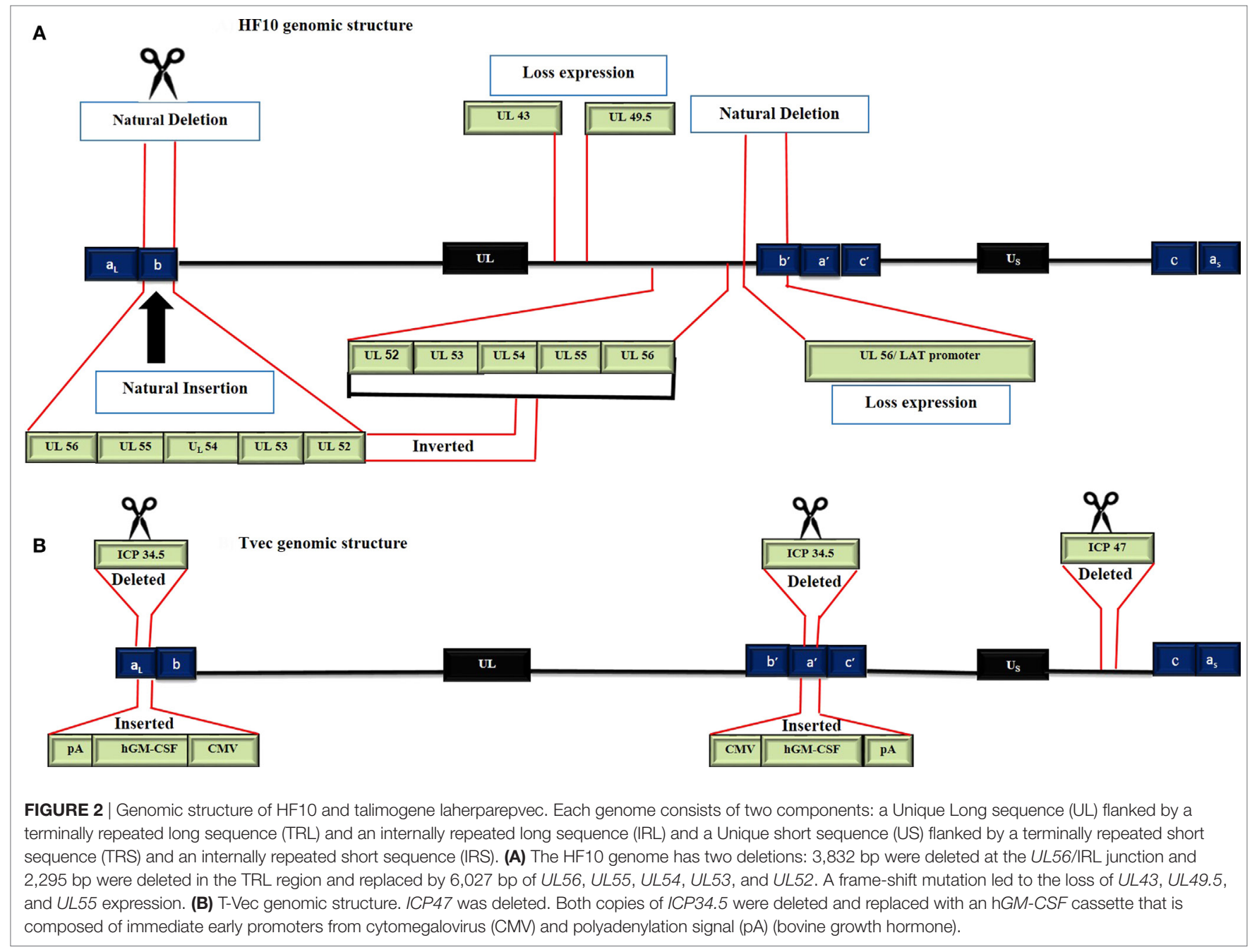

TABLE 2 | Genomic comparison of HF10 and other herpes simplex virus-1 oncolytic viruses (OVs).

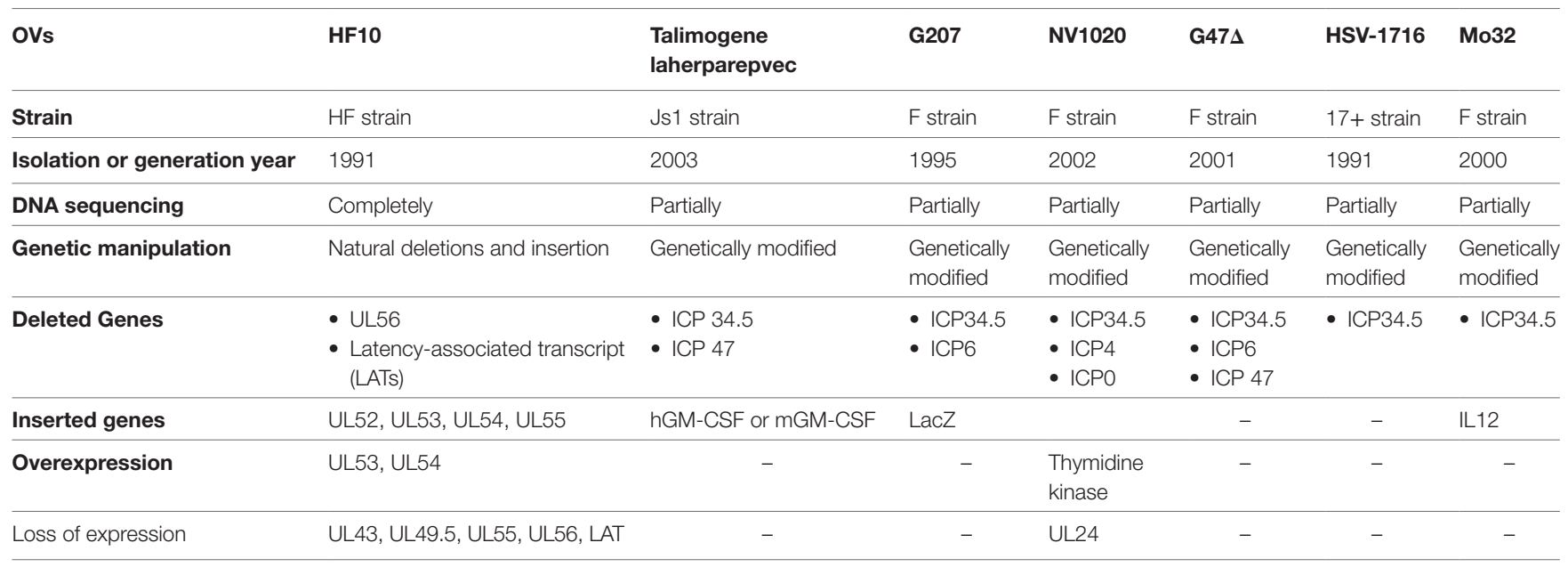

\section{UL43: ( $\gamma$ Gene, Accessory Gene)}

The HSV-1 UL43 gene acts as a $\gamma$ accessory gene. UL43 mRNA encodes a hydrophobic transmembrane protein (14) that is conserved in the $\alpha$ and $\gamma$ herpesviruses but absent in $\beta$ herpesviruses
(15-17). The UL43 protein is dispensable for viral growth in cell culture. Deletion of UL43 does not impair characteristics including virus entry, cell-cell fusion in vitro, viral replication in vivo, or neuroinvasiveness (18). Another study mentioned that 
HSV $17^{\text {UL43- }}$ has the ability to infect 40 to $60 \%$ of dendritic cells in vitro but the role of this deletion remains unclear (19). Thus, the lack of UL43 expression may play a role in the direct interaction between HF10 and antigen-presenting cells (dendritic cells) to enhance the immune response.

\section{UL49.5: $(\gamma$, Core Gene)}

The UL49.5 gene is a $\gamma$ core gene that is conserved in all HSVs. It encodes a type 1 transmembrane glycoprotein $\mathrm{N}(\mathrm{gN})$. This $\mathrm{gN}$ forms a heterodimeric complex with glycoprotein $\mathrm{M}(\mathrm{gM})$ $(20,21)$. UL49.5 homologs of HSV-1 have no effect on the transporter associated with antigen processing function (TAP) $(20,22)$. Hence, UL49.5 deletion is likely involved in the syncytial (syn) phenotype of HF10 while the effect of this deletion on the oncolytic capacity of HF10 remains unclear.

\section{UL53: ( $\gamma$, Accessory Gene)}

UL53 encodes glycoprotein $\mathrm{K}(\mathrm{gK})$ protein. gK regulates $\mathrm{HSV}$ egression from infected cells. $\mathrm{gK}$ is the most common locus of syn mutations. HF10 has duplicated UL53, which leads to gK overexpression, which causes accumulation of virus in the perinuclear space of infected cells as long as there are defects in viral egression (10). The accumulation of virus in cells accounts for a margin of safety when HF10 is inoculated into humans, as no shedding of virus to other organs has been observed. Previous studies have reported that $\mathrm{gK}$ prevents the formation of syncytia $(23,24)$. However, HF10 forms complete syncytia in vitro in different cell lines.

\section{UL55: ( $\gamma$, Accessory Gene)}

UL55 acts as a $\gamma$ accessory gene. UL55 mRNA encodes a nonstructural protein that is associated with sites of virion assembly. Previous studies have shown that UL55 is not necessary for intraperitoneal virulence and establishment of latency in mice $(25,26)$.

\section{UL56: ( $\gamma$, Accessory Gene)}

The UL56 gene is located at the right end of the unique long region of the HSV-1 genome (26). During acute infection, HSV-1 UL56 is naturally expressed; it is considered a component of the HSV-1 virion (27). UL56 is involved in the pathogenicity and latency of HSV-1. Lack of UL56 expression may be involved in viral neuroinvasiveness (28). A previous study has reported that the deletion of UL56 from the HSV-1 strain HFEM is pathogenic in tree shrews (29).

\section{Latency-Associated Transcripts}

Latency-associated transcripts are expressed during virus latency. LATs play a role in neuroinvasiveness and reactivation from latency. One study has reported a correlation between LATs and ICP34.5 deletion compared with wild-type virus. LATs alone and ICP34.5 alone each reduced spontaneous reactivation by $10-30 \%$ and $10 \%$, respectively, compared to wild type. However, deletion of both LATs and ICP34.5 led to undetectable levels of reactivation, even when the amount of virus was increased to $10^{8} \mathrm{pfu}$ (30). Therefore, the lack of LATs in the HF10 genome leads to suppression of reactivation from latency and supports the safety margin in the long-term, after treatment.

\section{Genomic Deletions and Insertions in HF10 and Other HSV OVs}

The identification of viral genes provides a strategy for genetically modifying OVs. To date, there are seven HSV-1 OVs (Table 2) being investigated in clinical trials. When we compare the genomic structure of OVs, we can see that the deletions and insertions of genes in HF10 are different from those in other OVs. ICP34.5 is deleted in HSV-1 OVs used in clinical trials, but present in HF10. ICP34.5 is thought to be involved in HSV neurovirulence. However, the exact mechanism by which HSVs induce encephalitis is unclear (31). HSV-1 OVs are classified according to the number of modified genes. First-generation OVs have only one modified gene (ICP34.5 deletion), such as HSV-1716 [ICP34.5(-)] (32). Second-generation OVs have several gene deletions or insertions, and include OVs, such as HF10, NV1020 [ICP34.5(-), ICP4(-), ICP0(-), TK(+)] (33), G207 [ICP34.5(-), ICP6(-), LacZ(+)] (34), and G47D [ICP6(-), ICP34.5(-), $\operatorname{ICP} 47(-)]$ (35). Third-generation OVs include therapeutic genes such as T-Vec $[G M-C S F(+) / I C P 34.5(-) / I C P 47(-)](13)$, and Mo32 [ICP34.5(-)/IL12(+)] (36).

\section{PRECLINICAL STUDIES OF HF10 AS MONOTHERAPY}

After investigating genomic changes in HF10, many investigators evaluated the oncolytic effect of HF10 in different malignant tumor models (Figure 3). Preclinical studies were conducted to evaluate the effect of HF10 replication on tumor selectivity and antitumor efficacy. HF10 was evaluated in vitro against Colon 26 and melanoma B16 cell lines, which showed that HF10 VP mediate cell-cell fusion to form enlarged multinucleated cells (syncytia formation). Furthermore, the therapeutic efficacy of HF10 was studied in murine and human breast cancer in vitro animal models. HF10 was also investigated in human and murine bladder cancer cell lines and in disseminated peritoneal metastasis.

To compare the antitumor effect and genomic structure of OVs, HSV-1 hrR3 [ICP6(-)] was chosen as a control due to the deletion of the UL39 gene. UL39 is also deleted in G207 and G47D HSV OVs. UL39 encodes ICP6, the large subunit of ribonucleotide reductase, which is required for viral replication in non-dividing cells $(37,38)$. However, the deletion of UL39 was postulated to increase the tumor selectivity of hrR3. HF10 induced complete syncytia formation in Colon 26 and melanoma B16 cell lines in vitro, while hrR3 induced a partial cytopathic effect. Furthermore, in a peritoneal tumor model, injection of $1 \times 10^{7}$ pfu of HF10 showed a more potent antitumor response, with a long-term survival rate over 90 days, than the same dose of hrR3 (39). Two studies have confirmed that HF10 replication was higher than hrR3 replication by 10 -fold in CT26 cell and NfSa Y83 fibrosarcoma cells $(40,41)$. One limitation of hrR3 was elevated levels of neutralizing antibodies against hrR3 after 5 days of intraperitoneal inoculation (42). In addition, Luo et al. reported that HF10 has a greater bystander effect than hrR3 due 


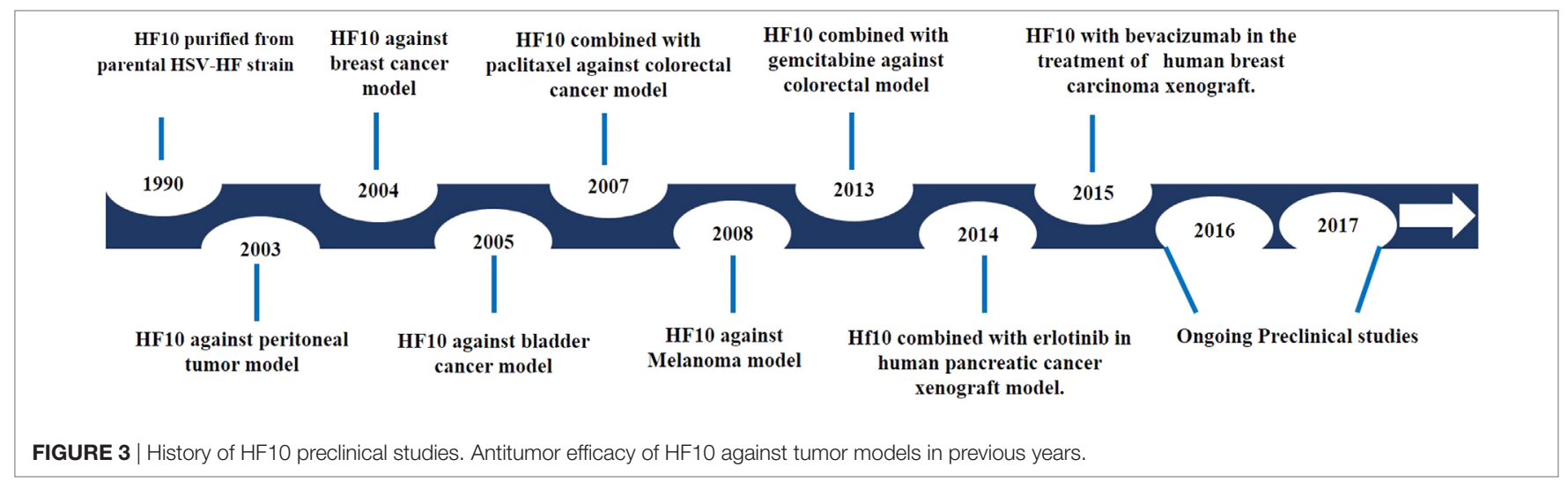

to enhanced expression of connexin 43 subunits (43). Regarding other genetic deletions, Oncovex ${ }^{I C P 34.5(-), I C P 47(-)}$ induced a classic cytopathic effect against human cell lines including HT1080 (fibrosarcoma), HCT 116 (human colonic carcinoma), CAPAN-1 (human pancreatic adenocarcinoma), and BHK (hamster normal baby kidney) cells (44). Therefore, natural deletions in HF10 may increase tumor selectivity, replication, cytopathic effect, and bystander effect compared with known deletions in other HSV OVs.

HF10 viral replication and cytotoxicity has also been studied in human and mouse melanoma cell lines (G-361 cells and clone M3 cells). HF10 induced 100\% cell lysis in the clone M3 cell line after $48 \mathrm{~h}$ at MOI 3 and 0.3 . Even at MOI $0.03,92.6 \%$ of melanoma cells were lysed $72 \mathrm{~h}$ after infection (45). T-Vec was studied in the SK-MEL-28 melanoma cell line. At MOI 0.1 and 1, T-Vec caused 48 and $89 \%$ cell death, respectively, after $24 \mathrm{~h}$. At $48 \mathrm{~h}$ after infection, T-Vec induced 84 and $100 \%$ cell death, respectively (EMEA/H/C/002771/0000). In an in vivo study, HF10 significantly reduced tumor growth in a subcutaneous melanoma model. Complete survival was shown in an intraperitoneal melanoma model without any obvious adverse effects. The antitumor efficacy and safety of HF10 were supported by detection of HF10 antigens with lymphoid cells and polymorphonuclear cells for at least 7 days after treatment (45). Recently, the B16F10 melanoma cell line, which lacks the expression of HSV entry receptors, was modulated to express the HSV-1 entry receptor Nectin1. A preliminary result with $\mathrm{T}-\mathrm{Vec}$ showed sensitivity against Nectin1expressing B16F10 in vitro and prolonged survival in an in vivo model (46).

Studies were extended to determine HF10 cellular tropism in other tumor models. The therapeutic efficacy of HF10 was studied in murine and human breast cancer animal models. HF10 efficiently replicated with high cytolytic effect in human and mouse breast cancer cell lines (MCF-7 and YMB-1, respectively). After $48 \mathrm{~h}, \mathrm{HF} 10$ lysed almost all cells at MOI 3 and 0.3 . However, HF10 replicated poorly in the MM102-TC mouse breast cancer cell line, even with increasing MOI titers. With inoculation of $1 \times 10^{7} \mathrm{pfu}$ of HF10, there was suppression of tumor growth with prolonged survival rates up to 120 days without any neurologic or toxic side effects (47). In another study, HF10 and T-Vec were evaluated in a human breast adenocarcinoma cell line (MDA-MB-231).
At MOI 1, HF10 caused approximately 50 and $90 \%$ cell death after 24 and $48 \mathrm{~h}$ post infection, respectively (48), while at the same MOI, T-Vec induced only 13.6 and $64.4 \%$ cell death after 24 and $48 \mathrm{~h}$ post infection, respectively (EMEA/H/C/002771/0000). In summary, HF10 with natural deletions had a significant oncolytic effect against human breast cancer cell lines.

Furthermore, the oncolytic effect of HF10 was investigated in human and murine bladder cancer cell lines (T24 and MBT-2) in vitro and also in a disseminated peritoneal metastasis model and a bladder cancer model. At MOI 3, HF10 replicated well in both T24 and MBT-2 cell lines and induced complete cell death by $48 \mathrm{~h}$. In addition, serial HF10 treatments significantly prolonged survival rates in both models. HF10 safety and selectivity were supported by the presence of HSV antigens in the bladder on day 1 after intravesical treatment without shedding to other organs (49). These results suggested that HF10 has promising effects in a bladder cancer model and should be studied in a clinical trial. Chemotherapeutic or immunotherapeutic agents have not yet been approved for the treatment of bladder cancer due to the lack of effectiveness. Among OVs, only one adenovirus CG0070 ${ }^{G M-C S F(+)}$ phase II/III study is ongoing (NCT01438112); a durable response was observed in a phase I study (50).

Taken together, all the preclinical data on HF10, such as the loss of UL56, LATs, UL43, and UL49.5 expression and UL53 overexpression from the HF10 genome, lead to the following characteristics: innately high tumor selectivity, high viral replication, complete cytopathic effect, mediation of a highly potent bystander effect, and potent antitumor efficacy.

\section{PRECLINICAL STUDIES OF HF10 AS COMBINATION THERAPY}

To date, OVs have not shown serious toxicities or any therapeutic resistance, in contrast to chemotherapeutic drugs that cause severe dose-limiting toxicities and emerging cell resistance. As each approach has different mechanisms of action, combination therapy with OVs and chemotherapy enhances the antitumor effect with limited toxic side effects. A number of chemotherapeutic drugs are able to modulate the activities of myeloid-derived suppressor cells (MDSCs) and regulatory $\mathrm{T}$ cells in the suppressive tumor 
microenvironment. Gemcitabine (GEM) inhibits MDSCs and enhances antitumor immune responses through $\mathrm{T}$ cell expansion (51). To date, GEM has been extensively investigated in combination with many OVs in different malignancies, including pancreatic cancer (52-56), renal cell carcinoma (57), and lung cancer (58, 59). Esaki et al. evaluated the synergistic effect between HF10 and GEM in a bilateral colorectal cancer model. After 3 days of GEM treatment, HF10 was injected at a dose of $1 \times 10^{7}$ pfu for 3 days to avoid possible interference with its replication. The study showed complete reduction of tumor size when HF10 was injected on the same side or even on the contralateral side. The oncolytic effect was enhanced by a significant decrease in $\mathrm{CD} 11 \mathrm{~b}^{+} / \mathrm{F} 4 / 80^{+}$macrophages and $\mathrm{CD} 11 \mathrm{~b}^{+} / \mathrm{Gr}-1^{+}$MDSCs after GEM injection (60). GEM is one of the first-line therapeutic agents against pancreatic carcinoma with a median survival rate 4.4-5.6 months $(61,62)$. Unfortunately, combination therapy with other cytotoxic agents produced intolerable toxicities without any added benefits. In contrast, HF10 had a promising antitumor effect with a high safety margin in the investigator-initiated clinical studies for pancreatic cancer. Hence, HF10 will be an ideal agent to combine with GEM to achieve a high antitumor effect against pancreatic cancer with minimal side effects.

Regarding other chemotherapeutic drugs, paclitaxel induces cell death through mitotic arrest due to its effect on microtubule stabilization (63). HF10 has been combined with paclitaxel to enhance antitumor efficacy in in vitro and in vivo immunocompetent colorectal cancer models. Paclitaxel did not interfere with the replication or cytotoxicity of HF10 with CT26 cells in vitro. Paclitaxel and HF10 combination therapy resulted in superior survival rates in peritoneal colorectal cancer compared with either treatment alone (40). High proportions of mitotic and apoptotic cells were reported in combination with Reovirus type 3 Dearing strain (ReoT3D) OV and paclitaxel in non-small cell lung cancer cells (58). Another study investigated combination therapy with paclitaxel plus oncolytic Rhabdovirus Maraba MG1 virus in breast cancer, which showed controlled tumor growth and prolonged survival (64).

As with other OVs, the antitumor activity of HF10 depends on two mechanisms of action: selective replication within tumor cells causing tumor cell bursting and spreading and expression of tumor antigens, which induce an antitumor immune response (65). Erlotinib, an epidermal growth factor receptor (EGFR) tyrosine kinase inhibitor, binds to the ErbB-1 receptor, thus inhibiting tyrosine kinase activity and disrupting the activity of downstream pathways, including the Ras/Raf mitogen-activated protein kinase, phosphoinositide-3 kinase/Akt, and Jak2/STAT3 pathways (66). In addition to inhibiting cell proliferation, erlotinib also induced apoptosis and anti-angiogenesis of tumor cells (67). Previous studies have reported that human pancreatic cancer cell lines BxPC-3 and PANC-1 cells express EGFR $(68,69)$. Yamamura et al. evaluated the antitumor efficacy of HF10 combined with erlotinib in human pancreatic xenograft in vitro and in vivo using BXPC-3 and PANC-1 (70). The study reported that HF10 induced cell lysis in both cell lines; however, erlotinib was only sensitive in BxPC-3 cells. Combination treatment with HF10 and erlotinib resulted in a more significant cell lysis effect in $\mathrm{BxPC}-3$ cells than with either HF10 or erlotinib alone. In BxPC-3 subcutaneous xenograft models, HF10 alone suppressed tumor growth more than erlotinib alone. However, in combination therapy, erlotinib caused high distribution of HF10, resulting in a significant tumor growth reduction compared with HF10 alone. Interestingly, the survival rate with HF10 alone was longer than with erlotinib alone (70).

The most important obstacle for OVs is the elevation of interstitial fluid pressure within tumors, which directly affects viral distribution (71). HSVs induce vascular endothelial growth factor (VEGF) production, which enhances angiogenesis in cells $(72,73)$. Bevacizumab is a monoclonal antibody suppressing tumor angiogenesis through inhibition of VEGF-A, which has been shown to be overexpressed in different solid tumors $(74,75)$. Tan et al. examined the oncolytic activity of HF10 in combination with bevacizumab in an experimental human breast carcinoma xenograft model (48). They showed that the MDA-MB-231 human breast cancer cell line has higher VEGF-A expression than the MC7 and T47D cell lines. By increasing MOI and time, HF10 alone induced cell cytotoxicity in the MDA-MB-231, MC7, and T47D cell lines. Bevacizumab did not induce any cell toxicity or interference with HF10 replication. In this study, two tumor models were established in BALB/c Slc-nu/nu mice bearing a single subcutaneous tumor or an advanced subcutaneous tumor. Intratumoral inoculation of HF10 $\left(10^{6} \mathrm{pfu}\right)$ and bevacizumab (5 $\mu$ g i.p.) significantly inhibited tumor growth in both models. In addition, immunohistochemical studies showed that the combination of HF10 and bevacizumab replicated more efficiently and with syncytia formation than HF10 treatment alone. More upregulation of VEGF-A with downregulation of CD31 was observed in endothelial cells after treatment with bevacizumab and HF10 compared with HF10 alone in both the single and advanced subcutaneous tumor models (48). A similar effect of bevacizumab was reported with other OVs, including adenoviruses (76), hrR3 (77), vaccinia virus (78), and reovirus (79).

\section{HF10 CLINICAL TRIALS}

\section{Phase I Clinical Trial in Breast Cancer}

HF10 has transitioned from preclinical to clinical trials to evaluate its therapeutic effect on human malignancies (Figure 4). The first clinical trial was performed from 2003 to 2006 by a team that included the surgery II, virology, and histopathology departments at the Graduate School of Medicine, Nagoya University, in Japan. The phase I clinical study evaluated the toxicity and efficacy of HF10 when directly injected intratumorally into cutaneous or subcutaneous metastatic nodules of recurrent breast cancers. All six patients had undergone mastectomy with recurrence after conventional therapies including chemotherapy, hormonal therapy, radiotherapy, and surgery. Patient age ranged from 48 to 76 years. They were seropositive for HSV and had metastatic recurrence in the skin (6/6), lymph nodes (4/6), lung $(2 / 6)$, brain $(1 / 6)$, and bone $(1 / 6)$. In addition, all patients had more than 10 cutaneous and subcutaneous nodules. The first nodule was injected with diluted HF10, with doses ranging from $1 \times 10^{4}$ to $5 \times 10^{5} \mathrm{pfu} / 0.5 \mathrm{~mL}$ for 3 days. Another nodule was injected with sterilized saline as a control (Table 3 ). All patients 


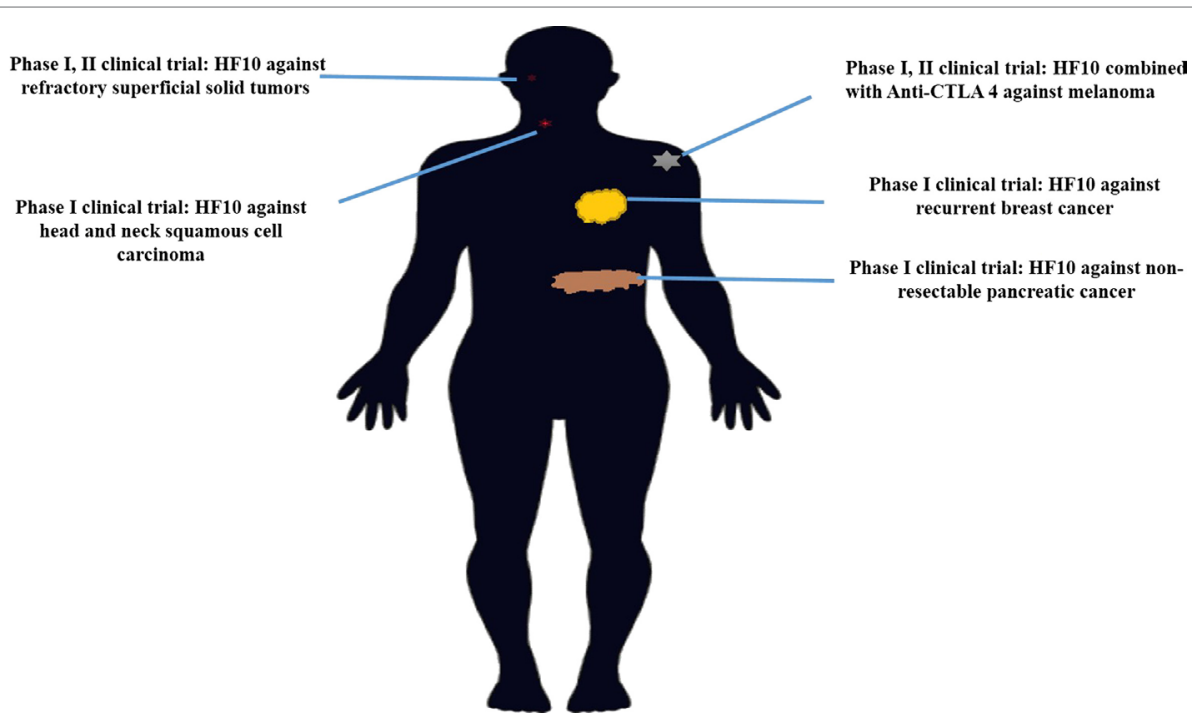

FIGURE 4 | History of HF10 clinical studies. Clinical trials of HF10 of various phases against different malignancies in previous years.

TABLE 3 | Profiles and responses of patients with metastatic breast cancer in a HF10 phase I clinical trial.

\begin{tabular}{|c|c|c|c|c|c|c|c|c|}
\hline Patient No. & $\begin{array}{c}\text { Age } \\
\text { (years) }\end{array}$ & Recurrence region & Prior therapy & $\begin{array}{c}\text { HF10 } \\
\text { pfu/0.5 mL } \times 3 \text { days }\end{array}$ & $\begin{array}{l}\text { No. of } \\
\text { Doses }\end{array}$ & Response & $\begin{array}{l}\text { Side } \\
\text { effects }\end{array}$ & Shedding \\
\hline 1 & 61 & Skin, LN, lung, brain & CT-, HT-, RT- & $1 \times 10^{4}$ & 1 & Moderate response & \multirow[t]{6}{*}{ None } & \multirow{6}{*}{$\begin{array}{l}\text { No shedding into } \\
\text { body fluids }\end{array}$} \\
\hline 2 & 62 & Skin, LN & CT-, RT- & $2 \times 10^{5}$ & 1 & Mild response & & \\
\hline 3 & 48 & Skin, LN, lung, bone & $\mathrm{SR}$ & $3 \times 10^{5}$ & 3 & Marked response & & \\
\hline 4 & 66 & Skin, LN & CT-, HT- & $5 \times 10^{5}$ & 1 & Moderate response & & \\
\hline 5 & 72 & Skin & S-, CT-, HT- & $5 \times 10^{5}$ & 3 & Complete response & & \\
\hline 6 & 76 & Skin & CT-, HT- & $5 \times 10^{5}$ & 3 & Not applicable & & \\
\hline
\end{tabular}

CT, chemotherapy; HT, hormonal therapy; RT, radiotherapy; SR, surgery.

tolerated the treatment well without any serious adverse effects. Histological examination showed nuclear viral inclusion bodies and adequate HF10 replication with high selectivity and distribution within malignant cells only. Tumor cell deformation was observed histologically, with 30 to $100 \%$ tumor death. Interestingly, a wide range of melting like fibrosis was observed after tumor cell destruction. There was considerable cytotoxic $\mathrm{CD}^{+} \mathrm{T}$ cell infiltration around tumor islets. Moreover, there was no change in the count of blood cells such as white blood cells and natural killer (NK) cells, or in the levels of cytokines, such as IL10, IL12, IFN $\alpha$, and IFN $\beta$. These data supported HF10 safety through selective replication within tumor cells without any severe side effects. Furthermore, HF10 induced a cytotoxic immune response against breast cancer with $\mathrm{CD}^{+}$and $\mathrm{CD}^{+}$ $\mathrm{T}$ cell infiltration $(80,81)$.

On the other hand, in the first clinical trial of T-Vec in 30 patients with cutaneous or subcutaneous metastases, the OV was injected into cutaneous or subcutaneous nodules in 14 breast cancer patients. Age ranged from 39 to 80 years; half of the patients were HSV seropositive and the other half were seronegative. $\mathrm{T}$-Vec doses ranged from $10^{6}$ to $10^{8} \mathrm{pfu} / \mathrm{mL}$ in 1 or 3 injections. In this study, there was no complete or even partial responses, but stable disease was observed without significant differences between seropositive or seronegative patients. Most patients tolerated the treatment well, with some side effects such as grade I pyrexia, low-grade anorexia, nausea, fatigue, and vomiting (82).

\section{Phase I Clinical Trial in HNSCC}

An additional study demonstrated the safety and efficacy of HF10 in a phase I dose-escalation pilot study at the School of Medicine, Nagoya University, in Japan, on February 12, 2005. Two patients with advanced HNSCC were HSV seropositive. They were classified with aT2N1M0 disease, with several skin metastases and rT0N3M1 disease, with lymph node and skin metastasis, respectively (Table 4). Adverse effects, virus replication, and immunological response were evaluated after intratumoral injection of HF10 $\left(1 \times 10^{5} \mathrm{pfu} / 1 \mathrm{~mL}\right.$ or $0.5 \mathrm{~mL}$ for 3 days $)$. In both patients, HF10 replicated well and induced tumor cell death with significant $\mathrm{CD}^{+}$or $\mathrm{CD}^{+}$cell infiltration. The patients had a lowgrade fever after injection but no other obvious adverse effects. As no significant regression in tumor size was observed on days 13 and 15 after treatment, higher doses of HF10 might be used in another trial (83). Five patients with positive or negative HSV serotype that had metastatic head and neck cancer received three doses of Oncovex ${ }^{G M-C S F}\left(10^{6}, 10^{7}\right.$, and $\left.10^{8} \mathrm{pfu} / 1 \mathrm{~mL}\right)$ for 3 days. Stable disease was observed without any complete or partial response. Some side effects such as pyrexia, low-grade anorexia, nausea, fatigue, and vomiting were observed (82). 
TABLE 4 | Profiles and responses of patients with metastatic HNSCC in a HF10 phase I clinical trial.

\begin{tabular}{lllllll}
\hline Patient & Age (years)/sex & Clinical stage & Prior therapy & $\begin{array}{l}\text { HF10 pfu/ } \\
\mathbf{m L} \times \mathbf{3} \text { days }\end{array}$ & Time & Response \\
\hline 1 & $79 /$ female & rTON3M1 & CT, RT & $10^{5}$ pfu/0.5 mL & 1 & No significant tumor regression \\
2 & $64 /$ male & rTON3M1 & CT, SR & $10^{5}$ pfu/ $1 \mathrm{~mL}$ & 1 & on day 13 or 15
\end{tabular}

HNSCC, head and neck squamous cell carcinoma; CT, chemotherapy; RT, radiotherapy; SR, surgery.

TABLE 5 | Profiles and responses of patients with metastatic pancreatic cancer in a HF10 phase I clinical trial.

\begin{tabular}{|c|c|c|c|c|c|c|c|c|}
\hline Patient & Age (years) & Clinical stage & HF10 PFU/0.5 mL/days & Time & Response & Survival (days) & Side effects & Shedding \\
\hline 1 & 68 & \multirow{8}{*}{$\begin{array}{l}\text { Invasive ductal } \\
\text { carcinoma }\end{array}$} & $1 \times 10^{5} \times 3$ & 1 & PD & 200 & \multirow{8}{*}{ None } & \multirow{8}{*}{$\begin{array}{l}\text { No shedding into body } \\
\text { fluids }\end{array}$} \\
\hline 2 & 61 & & $1 \times 10^{5} \times 3$ & 1 & SD & 166 & & \\
\hline 3 & 60 & & $5 \times 10^{5} \times 3$ & 3 & SD & 318 & & \\
\hline 4 & 52 & & $1 \times 10^{6} \times 3$ & 1 & PD & 98 & & \\
\hline 5 & 73 & & $1 \times 10^{6} \times 3$ & 3 & PR & 209 & & \\
\hline 6 & 76 & & $1 \times 10^{6} \times 3$ & 3 & SD & 315 & & \\
\hline 7 & 49 & & $1 \times 10^{6} \times 6$ & 6 & PD & 206 & & \\
\hline 8 & 64 & & $1 \times 10^{6} \times 6$ & 6 & PD & 113 & & \\
\hline
\end{tabular}

$P D$, progressive disease; $S D$, stable disease; $P R$, partial response.

\section{Phase I Clinical Trial in Pancreatic Cancer}

A phase I clinical trial was performed in eight male patients with invasive pancreatic ductal carcinoma from 2005 to 2009 at the School of Medicine, Nagoya University, in Japan. All eight patients were HSV seropositive because of safety concerns. Six patients received one injection of HF10 $\left(1 \times 10^{5} /\right.$ two patients, $5 \times 10^{5} /$ one patient, and $1 \times 10^{6} /$ three patients) per day for three consecutive days. After 3 days of injections, the patients were given no further treatment for 30 days and monitored for adverse and therapeutic effects. The first dose of $0.5 \mathrm{~mL}$ was injected in four sites or as $2.0 \mathrm{~mL}$ during laparotomy. The other two doses were injected using an intratumoral catheter inserted at the time of surgery. Moreover, the last two patients received an additional injection of $10^{6} \mathrm{pfu} / 1.0 \mathrm{~mL}$ HF10 once a week for total of 3 weeks via endoscopic ultrasound (Table 5). All patients tolerated the treatment well without any observed adverse effects after treatment. Three patients showed declines in the tumor marker CA19-9. There was no HSV shedding into the blood or body fluids based on plaqueforming assays at this time. HF10 envelope protein was also detected in autopsy specimens with infiltrations of macrophages, $\mathrm{CD}^{+}$and $\mathrm{CD}^{+}$cells, and activation of NK cells, suggesting that HF10 enhances antitumor immunity. The response to treatment was classified as stable disease in three patients, partial response in one patient, and progressive disease in four patients. Survival time ranged from 98 to 318 days, with an average of 180 days. These results suggested that higher doses of HF10 can be used in future trials $(84,85)$.

\section{Phase I and Phase II Clinical Trials in Refractory Superficial Cancers and Melanoma in the US}

A phase I clinical trial in patients with refractory superficial cancers and melanoma was conducted at the University of Pittsburgh in the United States. This trial evaluated the tolerability and efficacy of HF10 therapy in 26 patients, including HSV seropositive and seronegative patients, with refractory superficial cancers and melanoma. The trial was divided into two stages. In Stage 1, patients received a single HF10 dose at $1 \times 10^{5}, 3 \times 10^{5}, 1 \times 10^{6}$, or $1 \times 10^{7} \mathrm{pfu}$. In Stage 2, patients received four injections of HF10 at $1 \times 10^{6}$ to $1 \times 10^{7} \mathrm{pfu}$. The results showed that adverse events of any kind occurred in $34.6 \%$ of patients overall. Drugrelated adverse events included chills (11.5\%), fatigue (7.7\%), pyrexia (3.8), and injection site reaction (6\%). In comparison, T-Vec caused pyrexia (52\%), fatigue (48\%), and nausea (30\%) in 50 melanoma patients. Moreover, no significant difference was observed between HSV-1 seropositive and seronegative patients. In summary, HF10 was safe and well tolerated. The response rate was evaluated in 24 patients. Eight patients had stable disease. The reduction in tumor size in some patients ranged from 30 to $61 \%$. Interestingly, one patient showed pathological complete response after 4 months of treatment (86).

A phase II clinical trial of HF10 combination therapy was conducted in the United States. HF10 was combined with ipilimumab (anti-CTLA-4) in patients with unresectable or metastatic melanoma in this study (NCT02272855). A total of 46 patients were enrolled in this clinical trial, and results were evaluated in 44 patients. Regarding tumor growth inhibition, the best overall response (BOR) was evaluated by Immune-Related Response Criteria at 24 weeks. BOR was $41 \%$ (irCR: $16 \%$, irPR: $25 \%)$, clinical therapeutic efficacy was $68 \%$ (irCR + irPR + irSD), and irSD was $27 \%$. Regarding survival rate, median progressionfree survival was 19 months and median overall survival was 21.8 months. This combination showed a beneficial therapeutic effect as second-line therapy; in 20 patients, BOR was 30\% (87).

\section{FUTURE DIRECTIONS}

Over 14 years ago, HF10 was being investigated in various preclinical models, including disseminated peritoneal colon cancer, melanoma, pancreatic cancer, breast cancer, and bladder cancer. These studies have translated into successful clinical trials in different cancer types including recurrent metastatic breast cancer, 
recurrent HNSCC, advanced pancreatic cancer, refractory and superficial cancers, and melanoma. Although the data on HF10 in preclinical and clinical trials suggest that therapeutic applications can be developed with a high safety margin, combination therapies with either chemotherapy or immunotherapeutic agents are a promising approach in the near future. However, the ideal combination with HF10 still needs more investigation. As few OVs have shown efficacy against cancer stem cells and chemoresistant cells, more studies of HF10 against these types of cells are needed. For OVs in general, future studies must overcome physical tumor barriers that limit intravenous delivery.

\section{AUTHOR CONTRIBUTIONS}

IE: preparing manuscript, collecting data, designing, writing, and editing. $\mathrm{YN}$ : revising manuscript and providing critical

\section{REFERENCES}

1. Miest TS, Cattaneo R. New viruses for cancer therapy: meeting clinical needs. Nat Rev Microbiol (2014) 12(1):23-34. doi:10.1038/nrmicro3140

2. Whitley RJ, Kimberlin DW, Roizman B. Herpes simplex viruses. Clin Infect Dis (1998) 26(3):541-53. doi:10.1086/514600

3. Murphy FA, Fauquet CM, Bishop DH, Ghabrial SA, Jarvis A, Martelli GP, et al. Virus Taxonomy: Classification and Nomenclature of Viruses. New York, NY: Springer-Verlag (2012)

4. Martuza RL, Malick A, Markert JM, Ruffner KL, Coen DM. Experimental therapy of human glioma by means of a genetically engineered virus mutant. Science (1991) 252(5007):854-6. doi:10.1126/science.1851332

5. Greig SL. Talimogene laherparepvec: first global approval. Drugs (2016) 76(1):147-54. doi:10.1007/s40265-015-0522-7

6. Nishiyama Y, Kimura H, Daikoku T. Complementary lethal invasion of the central nervous system by nonneuroinvasive herpes simplex virus types 1 and 2. J Virol (1991) 65(8):4520-4.

7. Furlong D, Swift H, Roizman B. Arrangement of herpesvirus deoxyribonucleic acid in the core. J Virol (1972) 10(5):1071-4.

8. McCombs RM, Brunschwig JP, Mirkovic R, Benyesh-Melnick M. Electron microscopic characterization of a herpeslike virus isolated from tree shrews. Virology (1971) 45(3):816-20. doi:10.1016/0042-6822(71)90203-0

9. Adams R, Cunningham C, Davison MD, MacLean CA, Davison AJ. Characterization of the protein encoded by gene UL49A of herpes simplex virus type 1. J Gen Virol (1998) 79(4):813-23. doi:10.1099/0022-1317-79-4-813

10. Hutchinson L, Johnson DC. Herpes simplex virus glycoprotein K promotes egress of virus particles. J Virol (1995) 69(9):5401-13.

11. Adams M, LefkowitzE, King A, Bamford D, Breitbart M, Davison A, et al. Ratification vote on taxonomic proposals to the international committee on taxonomy of viruses (2015). Arch Virol (2015) 160(7):1837-50. doi:10.1007/s00705-015-2425-Z

12. Ushijima Y, Luo C, Goshima F, Yamauchi Y, Kimura H, Nishiyama Y. Determination and analysis of the DNA sequence of highly attenuated herpes simplex virus type 1 mutant HF10, a potential oncolytic virus. Microbes Infect (2007) 9(2):142-9. doi:10.1016/j.micinf.2006.10.019

13. Liu BL, Robinson M, Han ZQ, Branston RH, English C, Reay P, et al. ICP34. 5 deleted herpes simplex virus with enhanced oncolytic, immune stimulating, and anti-tumour properties. Gene Ther (2003) 10(4):292. doi:10.1038/sj.gt.3301885

14. Carter KL, Ward PL, Roizman B. Characterization of the products of the $\mathrm{U}$ sub(L)43 gene of herpes simplex virus 1: potential implications for regulation of gene expression by antisense transcription. J Virol (1996) 70(11):7663-8.

15. Biggin MD, Hudson GS, Gibson TJ, Deininger PL, Satchwell SC, Séguin C, et al. DNA sequence and expression of the B95-8 Epstein-Barr virus genome. Nature (1984) 310(5974):207-11. doi:10.1038/310207a0

16. Chee MS, Bankier AT, Beck S, Bohni R, Brown CM, Cerny R, et al. Analysis of the protein-coding content of the sequence of human cytomegalovirus strain AD169. Curr Top Microbiol Immunol (1990) 154:125-70. doi:10.1007/978-3-642-74980-3_6 considerations for manuscript design. TI: manuscript collecting data and editing. IB-V: revising manuscript and editing. MT, WZ, $\mathrm{NMu}, \mathrm{TM}, \mathrm{NMi}, \mathrm{HH}, \mathrm{SS}, \mathrm{BA}$, and YK: contributing to manuscript design and collecting data. HK: revising manuscript and providing critical considerations for manuscript design as well as final approval of the version to be published.

\section{ACKNOWLEDGMENTS}

This work was supported by a 2016 Grant-in-Aid for challenging Exploratory Research (16K15611). The authors are grateful to Prof. Yukihiro Nishiyama, who isolated the HF10 oncolytic virus at Department of Virology, Nagoya University Graduate School of Medicine. The authors would like to thank Ms. Kazue Kawamura for her significant efforts.

17. McGeoch DJ, Dalrymple MA, Davison AJ, Dolan A, Frame MC, McNab $\mathrm{D}$, et al. The complete DNA sequence of the long unique region in the genome of herpes simplex virus type 1. J Gen Virol (1988) 69(7):1531-74. doi:10.1099/0022-1317-69-7-1531

18. MacLean CA, Efstathiou S, Elliott ML, Jamieson FE, McGeoch DJ. Investigation of herpes simplex virus type 1 genes encoding multiply inserted membrane proteins. J Gen Virol (1991) 72(4):897-906. doi:10.1099/0022-1317-72-4-897

19. Samady L, Costigliola E, MacCormac L, McGrath Y, Cleverley S, Lilley CE, et al. Deletion of the virion host shutoff protein (vhs) from herpes simplex virus (HSV) relieves the viral block to dendritic cell activation: potential of vhs-HSV vectors for dendritic cell-mediated immunotherapy. J Virol (2003) 77(6):3768-76. doi:10.1128/JVI.77.6.3768-3776.2003

20. Crump CM, Bruun B, Bell S, Pomeranz LE, Minson T, Browne HM. Alphaherpesvirus glycoprotein $\mathrm{M}$ causes the relocalization of plasma membrane proteins. J Gen Virol (2004) 85(12):3517-27. doi:10.1099/vir.0.80361-0

21. McGeoch DJ, Rixon FJ, Davison AJ. Topics in herpesvirus genomics and evolution. Virus Res (2006) 117(1):90-104. doi:10.1016/j.virusres.2006.01.002

22. Klupp BG, Nixdorf R, Mettenleiter TC. Pseudorabies virus glycoprotein $\mathrm{M}$ inhibits membrane fusion. J Virol (2000) 74(15):6760-8. doi:10.1128/ JVI.74.15.6760-6768.2000

23. Avitabile E, Lombardi G, Gianni T, Capri M, Campadelli-Fiume G. Coexpression of UL20p and gK inhibits cell-cell fusion mediated by herpes simplex virus glycoproteins $\mathrm{gD}$, gH-gL, and wild-type $\mathrm{gB}$ or an endocytosisdefective gB mutant and downmodulates their cell surface expression. J Virol (2004) 78(15):8015-25. doi:10.1128/JVI.78.15.8015-8025.2004

24. Avitabile E, Lombardi G, Campadelli-Fiume G. Herpes simplex virus glycoprotein $\mathrm{K}$, but not its syncytial allele, inhibits cell-cell fusion mediated by the four fusogenic glycoproteins, gD, gB, gH, and gL. J Virol (2003) 77(12):6836-44. doi:10.1128/JVI.78.15.8015-8025.2004

25. Nishiyama Y. Herpes simplex virus gene products: the accessories reflect her lifestyle well. Rev Med Virol (2004) 14(1):33-46. doi:10.1002/rmv.409

26. Arvin A, Campadelli-Fiume G, Mocarski E, Moore PS, Roizman B, Whitley R, et al., editors. Human Herpesviruses: Biology, Therapy, and Immunoprophylaxis. Cambridge: Cambridge University Press (2007).

27. McGeoch DJ, Cunningham C, McIntyre G, Dolan A. Comparative sequence analysis of the long repeat regions and adjoining parts of the long unique regions in the genomes of herpes simplex viruses types 1 and 2. J Gen Virol (1991) 72(12):3057-75. doi:10.1099/0022-1317-72-12-3057

28. Koshizuka T, Goshima F, Takakuwa H, Nozawa N, Daikoku T, Koiwai O, et al. Identification and characterization of the UL56 gene product of herpes simplex virus type 2. J Virol (2002) 76(13):6718-28. doi:10.1128/JVI.76.13. 6718-6728.2002

29. Rösen-WoIff A, Lamadé W, Berkowitz C, Becker Y, Darai G. Elimination of UL56 gene by insertion of LacZ cassette between nucleotide position 116030 to 121753 of the herpes simplex virus type 1 genome abrogates intraperitoneal pathogenicity in tree shrews and mice. Virus Res (1991) 20(3):205-21. doi:10.1016/0168-1702(91)90076-8 
30. Perng G, Dunkel EC, Geary PA, Slanina SM, Ghiasi H, Kaiwar R, et al. The latency-associated transcript gene of herpes simplex virus type $1(\mathrm{HSV}-1)$ is required for efficient in vivo spontaneous reactivation of HSV-1 from latency. J Virol (1994) 68(12):8045-55.

31. Peters C, Rabkin SD. Designing herpes viruses as oncolytics. Mol Ther Oncolytics (2015) 2:15010. doi:10.1038/mto.2015.10

32. MacLean AR, Ul-Fareed M, Robertson L, Harland J, Brown SM. Herpes simplex virus type 1 deletion variants 1714 and 1716 pinpoint neurovirulence-related sequences in Glasgow strain 17+ between immediate early gene 1 and the 'a' sequence. J Gen Virol (1991) 72(3):631-9. doi:10.1099/0022-1317-72-3-631

33. Wong RJ, Kim S, Joe JK, Shah JP, Johnson PA, Fong Y. Effective treatment of head and neck squamous cell carcinoma by an oncolytic herpes simplex virus. J Am Coll Surg (2001) 193(1):12-21. doi:10.1016/S1072-7515(01)00866-3

34. Mineta T, Rabkin SD, Yazaki T, Hunter WD, Martuza RL. Attenuated multi-mutated herpes simplex virus-1 for the treatment of malignant gliomas. Nat Med (1995) 1(9):938-43. doi:10.1038/nm0995-938

35. Todo T, Martuza RL, Rabkin SD, Johnson PA. Oncolytic herpes simplex virus vector with enhanced MHC class I presentation and tumor cell killing. Proc Natl Acad Sci U S A (2001) 98(11):6396-401. doi:10.1073/pnas.101136398

36. Roth JC, Cassady KA, Cody JJ, Parker JN, Price KH, Coleman JM, et al. Evaluation of the safety and biodistribution of M032, an attenuated herpes simplex virus type 1 expressing hIL-12, after intracerebral administration to Aotus nonhuman primates. Hum Gene Ther Clin Dev (2014) 25(1):16-27. doi:10.1089/humc.2013.201

37. Goldstein DJ, Weller SK. Factor(s) present in herpes simplex virus type 1-infected cells can compensate for the loss of the large subunit of the viral ribonucleotide reductase: characterization of an ICP6 deletion mutant. Virology (1988) 166(1):41-51. doi:10.1016/0042-6822(88)90144-4

38. Aghi M, Visted T, DePinho RA, Chiocca EA. Oncolytic herpes virus with defective ICP6 specifically replicates in quiescent cells with homozygous genetic mutations in p16. Oncogene (2008) 27(30):4249-54. doi:10.1038/ onc. 2008.53

39. Takakuwa H, Goshima F, Nozawa N, Yoshikawa T, Kimata H, Nakao A, et al. Oncolytic viral therapy using a spontaneously generated herpes simplex virus type 1 variant for disseminated peritoneal tumor in immunocompetent mice. Arch Virol (2003) 148(4):813-25. doi:10.1007/s00705-002-0944-X

40. Shimoyama S, Goshima F, Teshigahara O, Kasuya H, Kodera Y, Nakao A, et al. Enhanced efficacy of herpes simplex virus mutant HF10 combined with paclitaxel in peritoneal cancer dissemination models. Hepatogastroenterology (2007) 54(76):1038-42.

41. Sugiura S, Goshima F, Takakuwa H, Sata T, Nakashima T, Nishiyama Y. Treatment of solid sarcomas in immunocompetent mice with novel, oncolytic herpes simplex viruses. Otolaryngol Head Neck Surg (2004) 130(4):470-8. doi:10.1016/j.otohns.2004.01.001

42. Herrlinger U, Kramm CM, Aboody-Guterman KS, Silver JS, Ikeda K, Johnston KM, et al. Pre-existing herpes simplex virus 1 (HSV-1) immunity decreases, but does not abolish, gene transfer to experimental brain tumors by a HSV-1 vector. Gene Ther (1998) 5(6):809-19. doi:10.1038/sj.gt.3300643

43. Luo C, Mori I, Goshima F, Ushijima Y, Nawa A, Kimura H, et al. Replicationcompetent, oncolytic herpes simplex virus type 1 mutants induce a bystander effect following ganciclovir treatment. J Gene Med (2007) 9(10):875-83. doi:10.1002/jgm.1085

44. Simpson GR, Han Z, Liu B, Wang Y, Campbell G, Coffin RS. Combination of a fusogenic glycoprotein, prodrug activation, and oncolytic herpes simplex virus for enhanced local tumor control. Cancer Res (2006) 66(9):4835-42. doi:10.1158/0008-5472.CAN-05-4352

45. Watanabe D, Goshima F, Mori I, Tamada Y, Matsumoto Y, Nishiyama Y. Oncolytic virotherapy for malignant melanoma with herpes simplex virus type 1 mutant HF10. J Dermatol Sci (2008) 50(3):185-96. doi:10.1016/j. jdermsci.2007.12.001

46. Cooke K, Estrada J, Zhan J, Mitchell P, Bulliard Y, Beltran PJ. Abstract 2351: development of a B16F10 cell line expressing mNectin1 to study the activity of OncoVEXmGM-CSF in murine syngeneic melanoma models. Cancer Res (2016) 76(14 Suppl):2351. doi:10.1158/1538-7445

47. Teshigahara O, Goshima F, Takao K, Kohno S, Kimata H, Nakao A, et al. Oncolytic viral therapy for breast cancer with herpes simplex virus type 1 mutant HF 10. J Surg Oncol (2004) 85(1):42-7. doi:10.1002/jso.20005
48. Tan G, Kasuya H, Sahin TT, Yamamura K, Wu Z, Koide Y, et al. Combination therapy of oncolytic herpes simplex virus HF10 and bevacizumab against experimental model of human breast carcinoma xenograft. Int J Cancer (2015) 136(7):1718-30. doi:10.1002/ijc.29163

49. Kohno S, Luo C, Goshima F, Nishiyama Y, Sata T, Ono Y. Herpes simplex virus type 1 mutant HF10 oncolytic viral therapy for bladder cancer. Urology (2005) 66(5):1116-21. doi:10.1016/j.urology.2005.05.041

50. Burke JM, Lamm DL, Meng MV, Nemunaitis JJ, Stephenson JJ, Arseneau JC, et al. A first in human phase 1 study of CG0070, a GM-CSF expressing oncolytic adenovirus, for the treatment of nonmuscle invasive bladder cancer. J Urol (2012) 188(6):2391-7. doi:10.1016/j.juro.2012.07.097

51. Le HK, Graham L, Cha E, Morales JK, Manjili MH, Bear HD. Gemcitabine directly inhibits myeloid derived suppressor cells in BALB/c mice bearing 4T1 mammary carcinoma and augments expansion of $\mathrm{T}$ cells from tumor-bearing mice. Int Immunopharmacol (2009) 9(7):900-9. doi:10.1016/j. intimp.2009.03.015

52. Leitner S, Sweeney K, Berg D, Davies D, Miranda E, Lemoine NR, et al. Oncolytic adenoviral mutants with E1B19K gene deletions enhance gemcitabine-induced apoptosis in pancreatic carcinoma cells and anti-tumor efficacy in vivo. Clin Cancer Res (2009) 15(5):1730-40. doi:10.1158/10780432.CCR-08-2008

53. Onimaru M, Ohuchida K, Nagai E, Mizumoto K, Egami T, Cui L, et al. Combination with low-dose gemcitabine and hTERT-promoter-dependent conditionally replicative adenovirus enhances cytotoxicity through their crosstalk mechanisms in pancreatic cancer. Cancer Lett (2010) 294(2):178-86. doi:10.1016/j.canlet.2010.01.034

54. Bhattacharyya M, Francis J, Eddouadi A, Lemoine NR, Hallden G. An oncolytic adenovirus defective in pRb-binding (d1922-947) can efficiently eliminate pancreatic cancer cells and tumors in vivo in combination with 5-FU or gemcitabine. Cancer Gene Ther (2011) 18(10):734-43. doi:10.1038/ cgt. 2011.45

55. Cherubini G, Kallin C, Mozetic A, Hammaren-Busch K, Müller H, Lemoine NR, et al. The oncolytic adenovirus $\operatorname{Ad} \Delta \Delta$ enhances selective cancer cell killing in combination with DNA-damaging drugs in pancreatic cancer models. Gene Ther (2011) 18(12):1157-65. doi:10.1038/gt.2011.141

56. Kangasniemi L, Parviainen S, Pisto T, Koskinen M, Jokinen M, Kiviluoto T, et al. Effects of capsid-modified oncolytic adenoviruses and their combinations with gemcitabine or silica gel on pancreatic cancer. Int J Cancer (2012) 131(1):253-63. doi:10.1002/ijc.26370

57. Wang H, Satoh M, Chen GP, Li DC, Hamada H, Arai Y. E1A, E1B double-restricted adenovirus enhances the cytotoxicity and antitumor activity of gemcitabine to renal cell carcinoma. Chin Med J (2011) 124(7):1082-7.

58. Sei S, Mussio JK, Yang QE, Nagashima K, Parchment RE, Coffey MC, et al. Synergistic antitumor activity of oncolytic reovirus and chemotherapeutic agents in non-small cell lung cancer cells. Mol Cancer (2009) 8(1):47. doi:10.1186/1476-4598-8-47

59. Liu D, Kojima T, Ouchi M, Kuroda S, Watanabe Y, Hashimoto Y, et al. Preclinical evaluation of synergistic effect of telomerase-specific oncolytic virotherapy and gemcitabine for human lung cancer. Mol Cancer Ther (2009) 8(4):980-7. doi:10.1158/1535-7163.MCT-08-0901

60. Esaki S, Goshima F, Kimura H, Murakami S, Nishiyama Y. Enhanced antitumoral activity of oncolytic herpes simplex virus with gemcitabine using colorectal tumor models. Int J Cancer (2013) 132(7):1592-601. doi:10.1002/ ijc. 27823

61. Burris HA III, Moore MJ, Andersen J, Green MR, Rothenberg ML, Modiano MR, et al. Improvements in survival and clinical benefit with gemcitabine as first-line therapy for patients with advanced pancreas cancer: a randomized trial. J Clin Oncol (1997) 15(6):2403-13. doi:10.1200/ JCO.1997.15.6.2403

62. Katopodis O, Souglakos J, Stathopoulos E, Christopoulou A, Kontopodis E, Kotsakis A, et al. Frontline treatment with gemcitabine, oxaliplatin and erlotinib for the treatment of advanced or metastatic pancreatic cancer: a multicenter phase II study of the Hellenic oncology research group (HORG). Cancer Chemother Pharmacol (2014) 74(2):333-40. doi:10.1007/s00280-014-2509-6

63. Weaver BA. How Taxol/paclitaxel kills cancer cells. Mol Biol Cell (2014) 25(18):2677-81. doi:10.1091/mbc.E14-04-0916

64. Bourgeois-Daigneault M, St-Germain LE, Roy DG, Pelin A, Aitken AS, Arulanandam R, et al. Combination of Paclitaxel and MG1 oncolytic virus 
as a successful strategy for breast cancer treatment. Breast Cancer Res (2016) 18(1):83. doi:10.1186/s13058-016-0744-y

65. Kaufman HL, Kohlhapp FJ, Zloza A. Oncolytic viruses: a new class of immunotherapy drugs. Nat Rev Drug Discov (2015) 14(9):642-62. doi:10.1038/ $\operatorname{nrd} 4663$

66. Yarden Y, Sliwkowski MX. Untangling the ErbB signalling network. Nat Rev Mol Cell Biol (2001) 2(2):127-37. doi:10.1038/35052073

67. Bareschino MA, Schettino C, Troiani T, Martinelli E, Morgillo F, Ciardiello F. Erlotinib in cancer treatment. Ann Oncol (2007) 18(Suppl 6):vi41. doi:10.1093/ annonc/mdm222

68. Arnoletti JP, Buchsbaum DJ, Huang Z, Hawkins AE, Khazaeli MB, Kraus MH, et al. Mechanisms of resistance to Erbitux (anti-epidermal growth factor receptor) combination therapy in pancreatic adenocarcinoma cells. J Gastrointest Surg (2004) 8(8):960-70. doi:10.1016/j.gassur.2004.09.021

69. Buck E, Eyzaguirre A, Barr S, Thompson S, Sennello R, Young D, et al. Loss of homotypic cell adhesion by epithelial-mesenchymal transition or mutation limits sensitivity to epidermal growth factor receptor inhibition. Mol Cancer Ther (2007) 6(2):532-41. doi:10.1158/1535-7163.MCT-06-0462

70. Yamamura K, Kasuya H, Sahin TT, Tan G, Hotta Y, Tsurumaru N, et al. Combination treatment of human pancreatic cancer xenograft models with the epidermal growth factor receptor tyrosine kinase inhibitor erlotinib and oncolytic herpes simplex virus HF10. Ann Surg Oncol (2014) 21(2):691-8. doi:10.1245/s10434-013-3329-3

71. Wojton J, Kaur B. Impact of tumor microenvironment on oncolytic viral therapy. Cytokine Growth Factor Rev (2010) 21(2):127-34. doi:10.1016/j. cytogfr.2010.02.014

72. Aghi M, Rabkin SD, Martuza RL. Angiogenic response caused by oncolytic herpes simplex virus-induced reduced thrombospondin expression can be prevented by specific viral mutations or by administering a thrombospondinderived peptide. Cancer Res (2007) 67(2):440-4. doi:10.1158/0008-5472. CAN-06-3145

73. Kurozumi K, Hardcastle J, Thakur R, Shroll J, Nowicki M, Otsuki A, et al. Oncolytic HSV-1 infection of tumors induces angiogenesis and upregulates CYR61. Mol Ther (2008) 16(8):1382-91. doi:10.1038/mt.2008.112

74. Shih T, Lindley C. Bevacizumab: an angiogenesis inhibitor for the treatment of solid malignancies. Clin Ther (2006) 28(11):1779-802. doi:10.1016/j. clinthera.2006.11.015

75. Ferrara N, Gerber H, LeCouter J. The biology of VEGF and its receptors. Nat Med (2003) 9(6):669-76. doi:10.1038/nm0603-669

76. Libertini S, Iacuzzo I, Perruolo G, Scala S, Ieran C, Franco R, et al. Bevacizumab increases viral distribution in human anaplastic thyroid carcinoma xenografts and enhances the effects of E1A-defective adenovirus d1922-947. Clin Cancer Res (2008) 14(20):6505-14. doi:10.1158/1078-0432.CCR-08-0200

77. Deguchi T, Shikano T, Kasuya H, Nawa A, Fujiwara S, Takeda S, et al. Combination of the tumor angiogenesis inhibitor bevacizumab and intratumoral oncolytic herpes virus injections as a treatment strategy for human gastric cancers. Hepatogastroenterology (2012) 59(118):1844-50. doi:10.5754/ hgel1566

78. Frentzen A, Yong AY, Chen N, Zhang Q, Weibel S, Raab V, et al. AntiVEGF single-chain antibody GLAF-1 encoded by oncolytic vaccinia virus significantly enhances antitumor therapy. Proc Natl Acad Sci U S A (2009) 106(31):12915-20. doi:10.1073/pnas.0900660106
79. Kottke T, Hall G, Pulido J, Diaz RM, Thompson J, Chong H, et al. Antiangiogenic cancer therapy combined with oncolytic virotherapy leads to regression of established tumors in mice. J Clin Invest (2010) 120(5):1551-60. doi:10.1172/JCI41431

80. Nakao A, Kimata H, Imai T, Kikumori T, Teshigahara O, Nagasaka T, et al. Intratumoral injection of herpes simplex virus HF10 in recurrent breast cancer. Ann Oncol (2004) 15(6):988-9. doi:10.1093/annonc/mdh225

81. Kimata H, Imai T, Kikumori T, Teshigahara O, Nagasaka T, Goshima F, et al. Pilot study of oncolytic viral therapy using mutant herpes simplex virus (HF10) against recurrent metastatic breast cancer. Ann Surg Oncol (2006) 13(8):1078-84. doi:10.1245/ASO.2006.08.035

82. Hu JC, Coffin RS, Davis CJ, Graham NJ, Groves N, Guest PJ, et al. A phase I study of OncoVEXGM-CSF, a second-generation oncolytic herpes simplex virus expressing granulocyte macrophage colony-stimulating factor. Clin Cancer Res (2006) 12(22):6737-47. doi:10.1158/1078-0432.CCR-06-0759

83. Fujimoto Y, Mizuno T, Sugiura S, Goshima F, Kohno S, Nakashima T, et al. Intratumoral injection of herpes simplex virus HF10 in recurrent head and neck squamous cell carcinoma. Acta Otolaryngol (2006) 126(10):1115-11171. doi:10.1080/00016480600702100

84. Nakao A, Kasuya H, Sahin TT, Nomura N, Kanzaki A, Misawa M, et al. A phase I dose-escalation clinical trial of intraoperative direct intratumoral injection of HF10 oncolytic virus in non-resectable patients with advanced pancreatic cancer. Cancer Gene Ther (2011) 18(3):167-75. doi:10.1038/ cgt. 2010.65

85. Kasuya H, Kodera Y, Nakao A, Yamamura K, Gewen T, Zhiwen W, et al. Phase I dose-escalation clinical trial of HF10 oncolytic herpes virus in 17 Japanese patients with advanced cancer. Hepatogastroenterology (2014) 61(131):599-605. doi:10.5754/hge14104

86. Ferris R, Gross ND, Nemunaitis JJ, Andtbacka RHI, Argiris A, Ohr J, et al. Phase I trial of intratumoral therapy using HF10, an oncolytic HSV-1, demonstrates safety in HSV+/HSV- patients with refractory and superficial cancers. J Clin Oncol (2014) 32(Suppl; abstr 6082):6082. doi:10.1200/ jco.2014.32.15_suppl.6082

87. Andtbacka RH, Ross MI, Agarwala SS, Taylor MH, Vetto JT, Neves RI, et al. Preliminary results from phase II study of combination treatment with HF10, a replication-competent HSV-1 oncolytic virus, and ipilimumab in patients with stage IIIb, IIIc, or IV unresectable or metastatic melanoma. J Clin Oncol (2016) 34(no. 15_suppl):9543-9543. doi:10.1200/JCO.2016. 34.15_suppl.9543

Conflict of Interest Statement: Maki Tanaka is an employee of Takara Bio Inc. The remaining authors report no conflicts of interest in this work.

Copyright @ 2017 Eissa, Naoe, Bustos-Villalobos, Ichinose, Tanaka, Zhiwen, Mukoyama, Morimoto, Miyajima, Hitoki, Sumigama, Aleksic, Kodera and Kasuya. This is an open-access article distributed under the terms of the Creative Commons Attribution License (CC BY). The use, distribution or reproduction in other forums is permitted, provided the original author(s) or licensor are credited and that the original publication in this journal is cited, in accordance with accepted academic practice. No use, distribution or reproduction is permitted which does not comply with these terms. 